\title{
ATELIERS DE HISTÓRIA DAARQUITETURA: ANÁLISE GRÁFICA, DESENHO E MODELOS ANALÍTICOS
}

TALLERES DE HISTORIA DE LA ARQUITETURA: ANÁLISIS GRÁFICO, DISEÑO Y MODELOS ANALÍTICOS

\section{HISTORY OF THE ARCHITECTURE WORKSHOPS: GRAPHIC ANALYSIS, DESIGN AND ANALYTICAL MODELS}

\section{COTRIM, MÁRCIO}

Doutor em Teoria e História da Arquitetura pela Universitat Politècnica de Catalunya. Professor do Departamento de Arquitetura e Urbanismo - DAU/UFPB e do Programa de Pós-Graduação em Arquitetura e Urbanismo - PPGAU/UFPB. E-mail: marciocotrim@gmail.com

\section{TINEM, NELCl}

Doutora em História da Arquitetura, História Urbana pela Universitat Politècnica de Catalunya. Professora do Departamento de Arquitetura e Urbanismo DAU/UFPB e do Programa de Pós-Graduação em Arquitetura e Urbanismo - PPGAU/UFPB. E-mail: ntinem@uol.com.br

\section{VIDAL, WYLNNA}

Doutoranda do Programa de Pós-Graduação em Arquitetura e Urbanismo - PPGAU/UFPB e Professora do Departamento de Arquitetura e Urbanismo - DAU/UFPB. E-mail:wylnna@yahoo.com.br

\section{RESUMO}

Os exercícios e a pesquisa que dão suporte a este ensaio partem do pressuposto de que as diversas formas de análise gráfica podem vir a conformar instrumentos importantes para a interação entre os conhecimentos de teoria, história e projeto de arquitetura e urbanismo. Assim, o propósito dos exercícios, é fazer com que os estudantes se detenham, por meio de produtos gráficos - modelos e desenhos analíticos - na observação criteriosa do edifício arquitetônico e comuniquem visualmente o resultado desse esforço. Como propõe Eisenman trata-se de proceder a uma "leitura em detalhe" da obra e assim revelar particularidades subjacentes ao projeto que, de outro modo, passariam despercebidas.

PALAVRAS-CHAVE: análise gráfica; projeto de arquitetura; teoria; história.

\section{RESUMEN}

Los ejercicios y la investigación que soportan este ensayo tienen como principio conseguir que las distintas formas de análisis gráfico puedan conformar instrumentos importantes para la interacción entre los conocimientos de teoría, historia y diseño de arquitectura e urbanismo. El propósito de esos ejercicios es proporcionar que los estudiantes mantengan el foco, por medio de productos gráficos - modelos e dibujos analíticos -, en la observación criteriosa del edificio arquitectónico y comunique visualmente el resultado de ese esfuerzo. Como propone Eisenman se trata de proceder a una "lectura en detalle" de la obra y revelar particularidades subyacentes al diseño que, de otro modo, pasarían desapercibidas.

PALABRAS-CLAVE: análisis gráfico; diseño de arquitectura; teoría; historia.

\section{ABSTRACT}

The exercises and research that support this essay have as principle get various forms of graphical analysis that can comply important instruments for interaction between the knowledge of theory, history, architectural design and urbanism. The purpose of these exercises is to provide that students keep the focus, through models and analytical drawings - graphic products in the judicious observation of architectural building and visually communicate the result of that effort. As proposed by Eisenman it is a "reading in detail" of the work and reveal underlying peculiarities to the design which, otherwise, would go unnoticed. KEYWORDS: graphical analysis; architecture design; theory; history.

\section{INTRODUÇÃO}

Os exercícios e a pesquisa ${ }^{1}$ que dão suporte a este ensaio partem do pressuposto de que as diversas formas de análise gráfica podem vir a conformar instrumentos importantes para a interação entre os conhecimentos de teoria, história e projeto de arquitetura e urbanismo.

Entende-se análise gráfica como um procedimento sistemático com a finalidade de aprofundar a compreensão de determinado objeto e que resulta na elaboração de um novo conjunto de informações (gráficas), as quais são tratadas aqui como desenhos analíticos. O termo dibujo analítico ou desenho analítico é proposto por Botella (2002, p.5) para designar o desenho-síntese resultante da manipulação/transformação de desenhos descritivos ou de representação. Esta transformação se dá em conformidade com o foco de interesse ou objetivo da análise, enfatizando determinados elementos e 
conformando um conjunto de informações, que pode ser considerado complementar aos desenhos de representação do objeto arquitetônico que, em essência, são predominantemente descritivos.

Figura 01: Atelier de história da arquitetura.

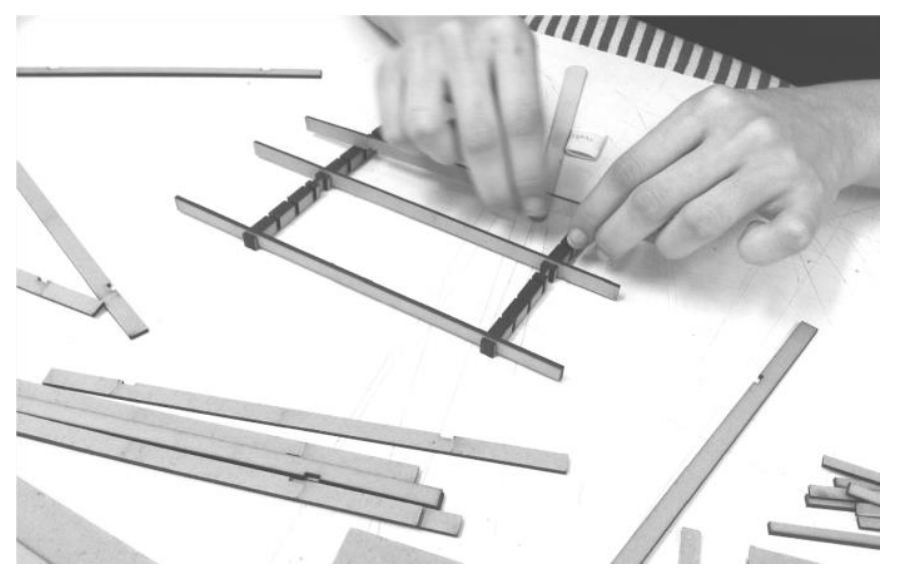

Foto: Márcio Cotrim.

Como recurso didático, Botella (2002) separa o desenho de arquitetura em dois tipos simetricamente opostos: descritivos ou de representação, aqueles cujo objetivo mais imediato é o de explicar um edifício; e analíticos, cuja finalidade seria a de explicar uma ideia. Enquanto o primeiro teria uma natureza mais objetiva, o segundo permanece no universo conceitual. Obviamente, entre estes dois polos há inúmeros matizes e todo desenho que representa um edifício também contém determinadas ideias.

O termo dibujo analítico, proposto por Botella, parece desviar-se, ainda que mantendo direções comuns, da ideia de diagrama, encontrada no dicionário da Real Academia Española, "dibujo geométrico que sirve para demostrar una proposición, resolver un problema o figurar de una manera gráfica la ley de variación de un fenómeno". E aproxima-se da definição proposta por Eisenman: "os diagramas atuam como uma série de instruções, tentam fazer legíveis as relações que um indivíduo pode não ver; subministram o que se chama uma estrutura conceitual para esse entendimento" (EISENMAN Apud BOTELLA, 2002).

$O$ processo de elaboração de desenhos analíticos permite deter a atenção nas relações conceituais possibilitando uma compreensão aprofundada do todo, em um ciclo que alterna operação de análise e operação de síntese. Por extensão, adotamos o termo modelo analítico para designar o tipo de modelo físico desenvolvido em exercícios propostos em sala de aula em algumas das disciplinas de História da Arquitetura da UFPB ${ }^{2}$, que extrapola o propósito recorrente de representações fisionômicas dos objetos estudados, resultando em modelos que, por vezes, dão ênfase a determinados atributos, muitas vezes imperceptíveis - seja experimentando efetivamente o edifício ou por meios de desenhos de representação mais tradicionais - evitando o papel exclusivo de redução da escala. Para nós, o modelo físico analítico se aproxima, de modo retroativo à lógica projetual, às maquetes de estudo. Segundo Fernando Alvarez Prozorovich, as maquetes de estudos (maquetas-boceto) estão associadas com a palavra de origem italiana machia, "mancha, ou esboço, croquis, rastro; que permite uma apropriação mais artística da maquete física, que tem o caráter de ideia, um conceito mais aberto que transmite sugestões de soluções diante de um programa". (PROZOROVICH, 2006).

Figura 02a e 02b: Atelier de história da arquitetura.

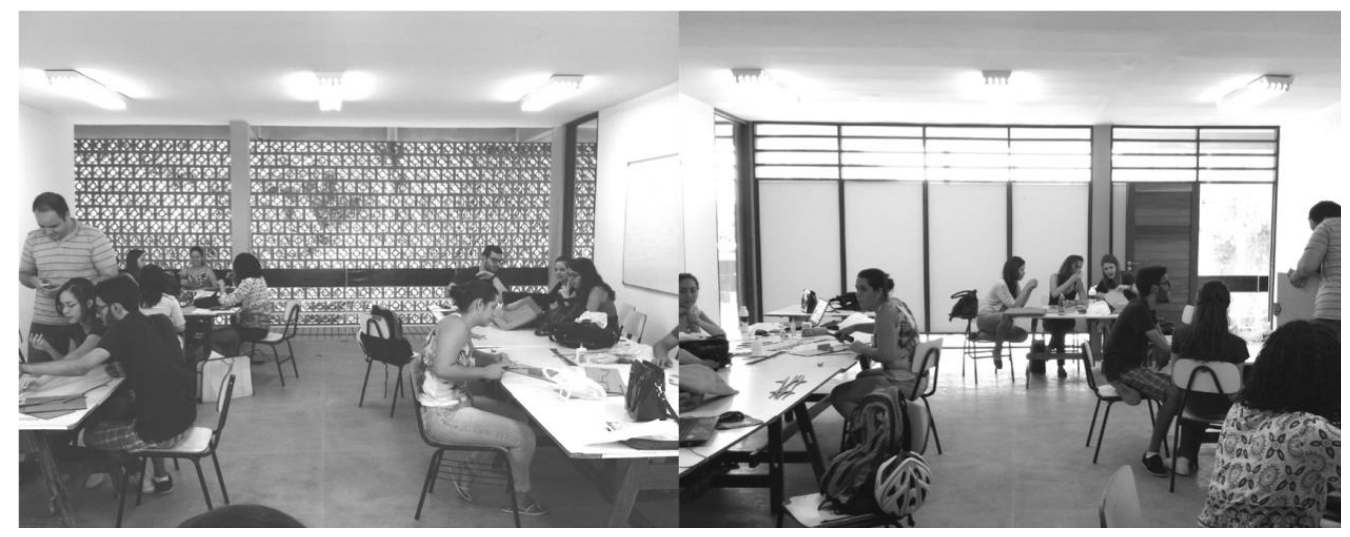

Foto: Márcio Cotrim. 
Figura 03: Atelier de história da arquitetura.

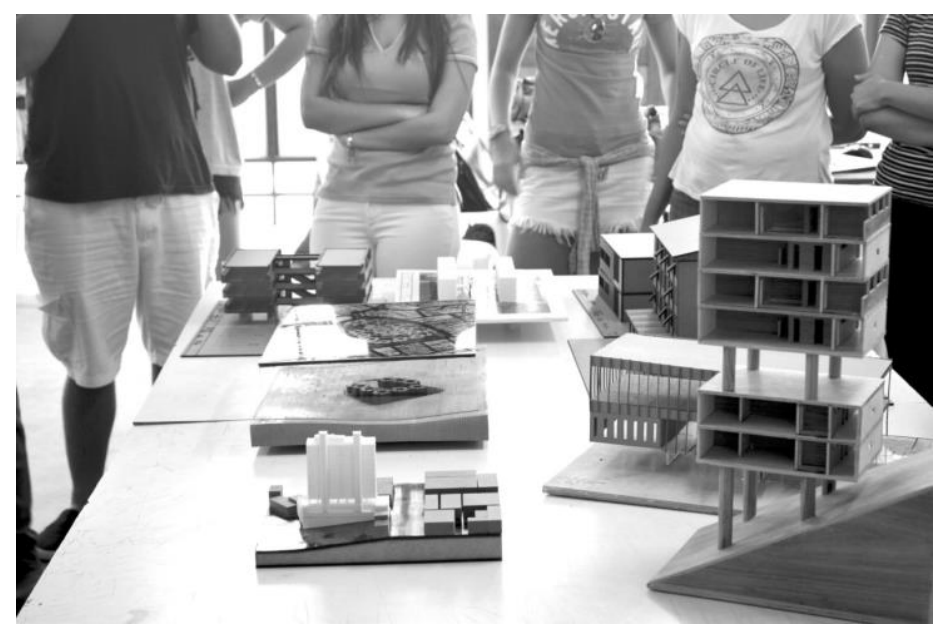

Foto: Márcio Cotrim.

\section{DESENVOLVIMENTO}

Assim, o propósito dos exercícios, é fazer com que os estudantes se detenham, por meio de produtos gráficos - modelos e desenhos analíticos - na observação criteriosa do edifício arquitetônico e comunique visualmente o resultado desse esforço. Como propõe Eisenman (2010), trata-se de proceder a uma "leitura em detalhe" da obra e assim revelar particularidades subjacentes ao projeto que, de outro modo, passariam despercebidas. Eisenman (2010, p.16) explica ao que se refere com a "leitura em detalhe", referindo-se aos ensinamentos de Rowe:

Em outras palavras que me preocupasse menos pelo que o olho vê - o ótico - e mais pelo que vê a mente - o visual. [...] chamamos "leitura em detalhe" a esta última ideia de "ver com a mente" (EISENMAN, 2010, p.16).

Figura 04: Atelier de história da arquitetura.

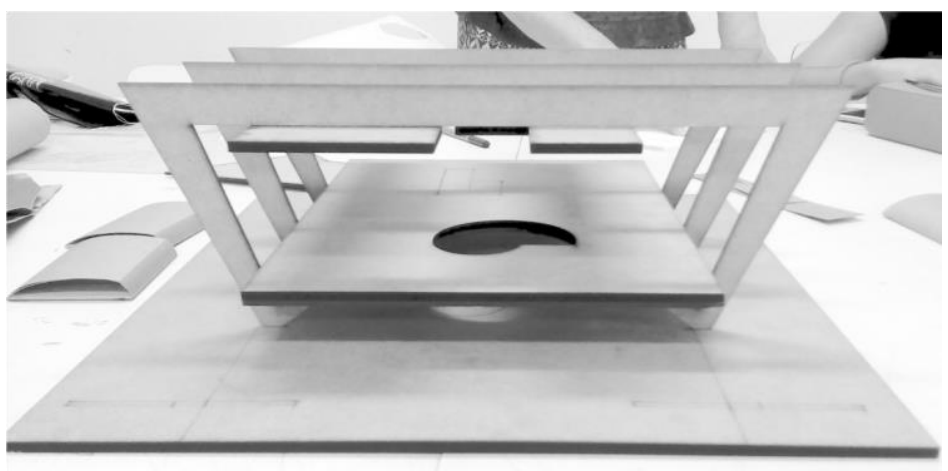

Foto: Márcio Cotrim

Ao aceitarmos a diferenciação proposta por Eisenman, os desenhos e modelos analíticos assumem papel fundamental como instrumentos de mediação entre o "óptico" e "visual", portanto, como facilitadores da leitura em detalhe.

Os exercícios dentro dos ateliers de história da arquitetura são estruturados em três etapas, mas marcados por um número expressivamente maior de passos concomitantes:

(1) aproximação ao objeto de estudo (um edifício) por meio de: (a) elaboração de registros gráficos descritivos, ou seja, a partir da elaboração do redesenho do projeto e da (b) elaboração do modelo digital, desenvolvido a partir de (c) material coletado em fontes diversas - registros gráficos obtidos em arquivos de prefeitura, em publicações especializadas, disponível em trabalhos acadêmicos, por meio de contato direto com o autor do projeto, ou por meio do levantamento físico da casa, registros fotográficos, entre outros. Um aspecto fundamental nesta etapa é a confrontação entre esses diversos materiais, visando identificar incoerências e contradições entre as diferentes formas de representação que normalmente exige um tipo de atenção que se aproxima da "leitura em detalhe" descrita anteriormente. 
(2) Em um segundo momento (após os passos simultâneos a, b e c) parte-se para a (d) elaboração do modelo físico analítico, ocasião em que se procura aprofundar o conhecimento sobre o objeto de estudo. $O$ procedimento para a elaboração do modelo varia de caso a caso, discutindo-se quais aspectos merecem ser "revelados", quais os materiais e escala são mais apropriados ao modelo físico, pela tangibilidade material que lhe é inerente e que permite ampliar a compreensão da obra e a aproximação de sua realidade física.

Figura 05: V. Savoye, projeto n3, Le Corbusier.

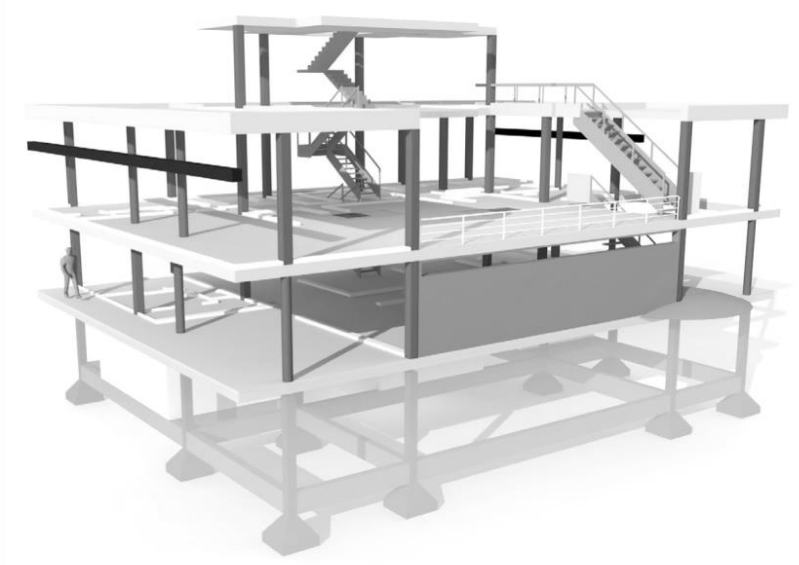

Fonte: LPPM.

(3) Por fim, elabora-se um produto síntese - tendo sido experimentado vídeos, documentários, ensaios, entre outros -, no qual se pretende - intervindo no material gráfico até o momento elaborado - (e) gerar novas informações, em forma de desenhos analíticos, que facilitem a leitura em detalhe.

A especificidade das diferentes etapas destes exercícios acaba criando um ambiente em sala de aula muito próximo ao de um atelier de projeto. Croquis, maquetes de estudo, rolos de desenho, misturam-se com livros, revistas e documentos.

O entendimento de uma obra torna-se mais fácil a partir do redesenho de seu projeto, apesar de exigir pesquisa, tempo de decantação das informações, visão crítica, além de dedicação e concentração no trabalho. Muito mais do que seria necessário em uma disciplina tradicional de história. Entretanto, muito mais dinâmico, interessante e profícuo.

Figura 06: Casa alta, 1959, Rio de Janeiro Sergio Bernardes.

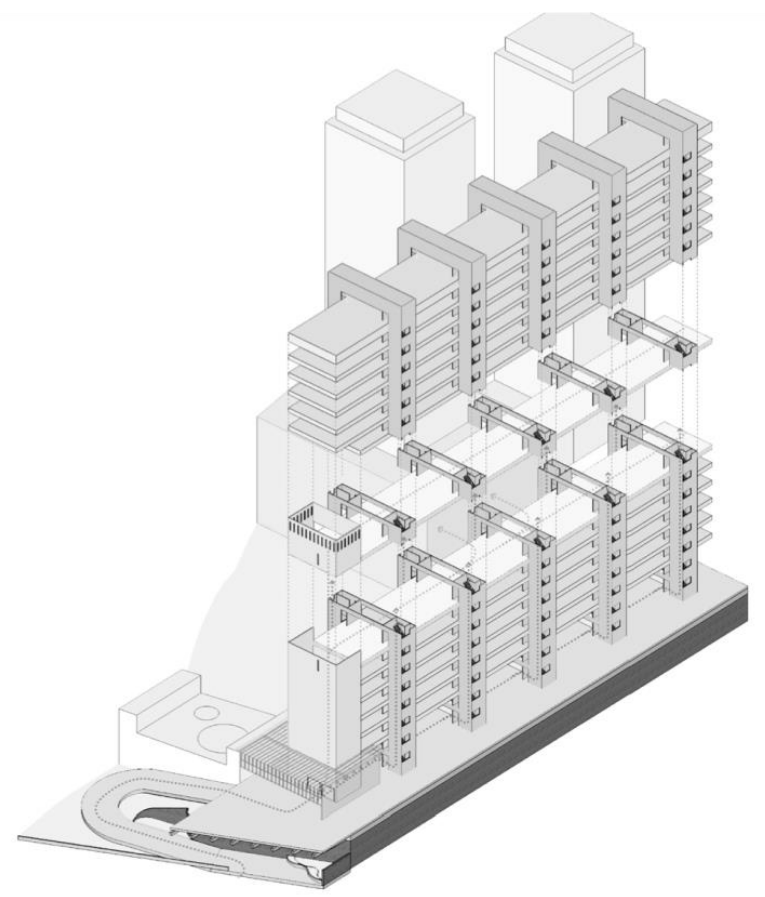


Fonte: LPPM.

Figura 07: Conjunto habitacional lagoinha, Belo Horizonte, 1940.

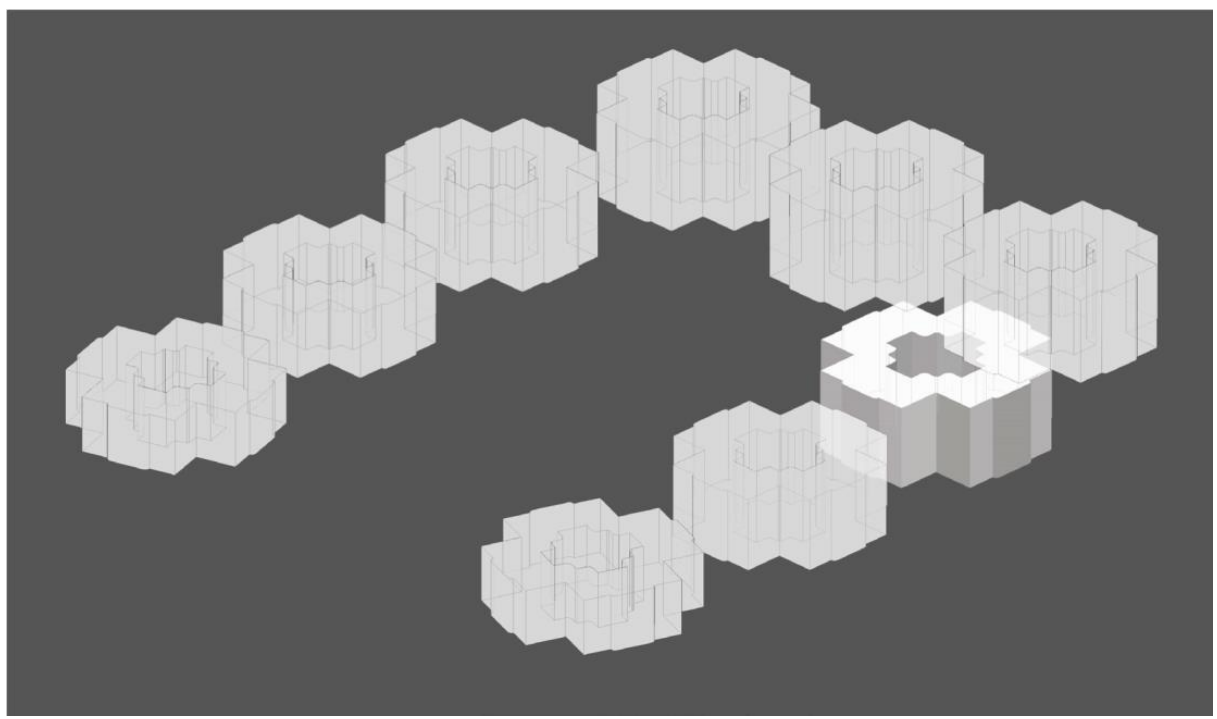

Fonte: LPPM.

Os modelos tridimensionais, digital e físico, construídos, por sua vez, além de incrementar a compreensão do objeto arquitetônico, vão dar sustentação a análise gráfica, podendo ser manipulados com base nas pesquisas realizadas e nas interpretações que vão surgindo, gerando produtos gráficos distintos para cada parâmetro de análise definido em cada obra estudada. Ou seja, o processo de conhecimento da obra é conduzido conforme as escolhas feitas pelo pesquisador.

Com tais procedimentos utilizados no atelier de história, o conhecimento de uma obra de um arquiteto transcende esse exercício e gera inferências relativas à produção geral, com auxílio de seminários/debates entre os alunos com seus exemplares arquitetônicos distintos, mas pertencentes a um mesmo movimento. Assim o aluno passa a conhecer, não somente a obra em questão, mas também a produção do arquiteto, sendo capaz de reconhecer suas influências, costumes, "assinatura", verificando os pontos recorrentes na sua obra ou, ao contrário, as exceções. Do mesmo modo, é possível estender o conhecimento do arquiteto ao movimento do qual ele faz parte.

Figura 08: Residência para ministro de estado, DF, 1965, João Filgueiras Lima Lele.

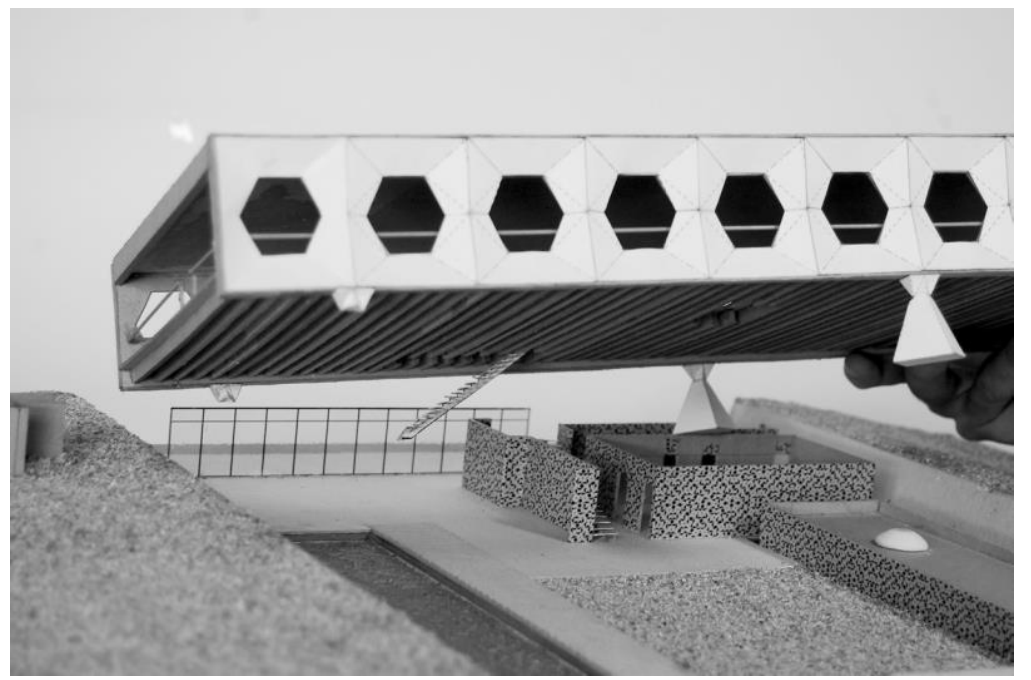

Fonte: LPPM

\section{CONSIDERAÇÕES FINAIS}

As experiências levadas a cabo desde 2010, quando esses exercícios começaram a ser aplicados e, desde então, aprimorados, levantam - a partir da utilização das ferramentas nas experiências estudadas e 
aplicadas no estudo das casas, objeto de estudo - questões fundamentais: (1) até que ponto e em que termos os modelos, físicos e digitais, servem como ferramenta indutora de conhecimento? (2) em que termos esse conhecimento rigoroso e detalhado de projetos exemplares, a partir de aspectos intrínsecos do fazer arquitetônico, facilita a aproximação entre as disciplinas de projeto e teoria/história? (3) Ou ainda, qual a contribuição dessa concepção de ensino para a prática profissional?

Como tentativa de resposta aos três questionamentos expostos pode-se explorar ao menos alguns temas:

O tipo de esforço exigido nestes exercícios é significativo, pois o retira o aluno da passividade de quem se limita exclusivamente a receber as informações transmitidas pelo professor e o converte em um alunopesquisador, que é obrigado a interpretar o material e os documentos que manuseia, bem como içar pontes com a informação anteriormente recebida, nas etapas mais tradicionais do curso.

As discussões desenvolvidas à luz de problemas, soluções e estratégias de natureza arquitetônica, como condição fundamental para a elaboração de qualquer discurso crítico, faz com que professor e aluno, ambos pesquisadores, evitem rótulos fáceis ou digressões em torno de curiosidades agradáveis que não contribuem para a compreensão das obras pesquisadas.

Figura 09: Residência Elias C. Cury, 1969, São Paulo, Artigas.

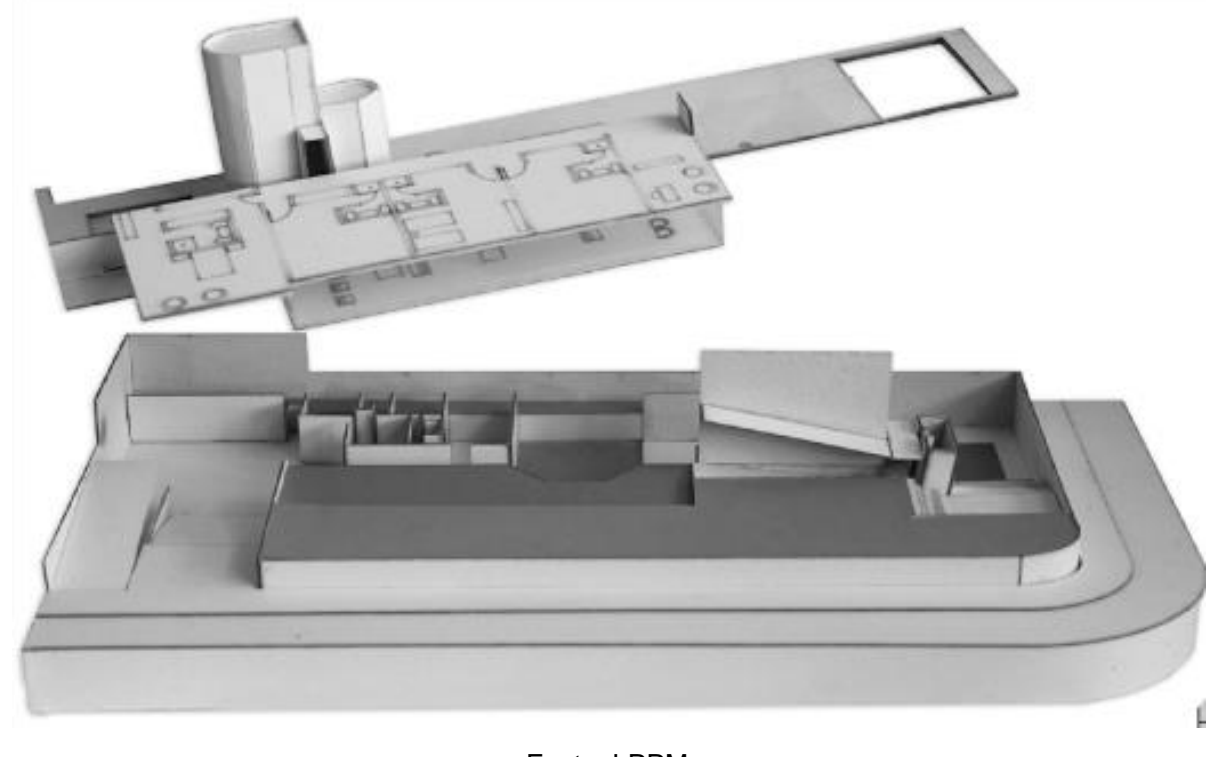

Fonte: LPPM.

Figura 10: Galeria Jardim, 1974, Buenos Aires, Mario Roberto Alvarez.

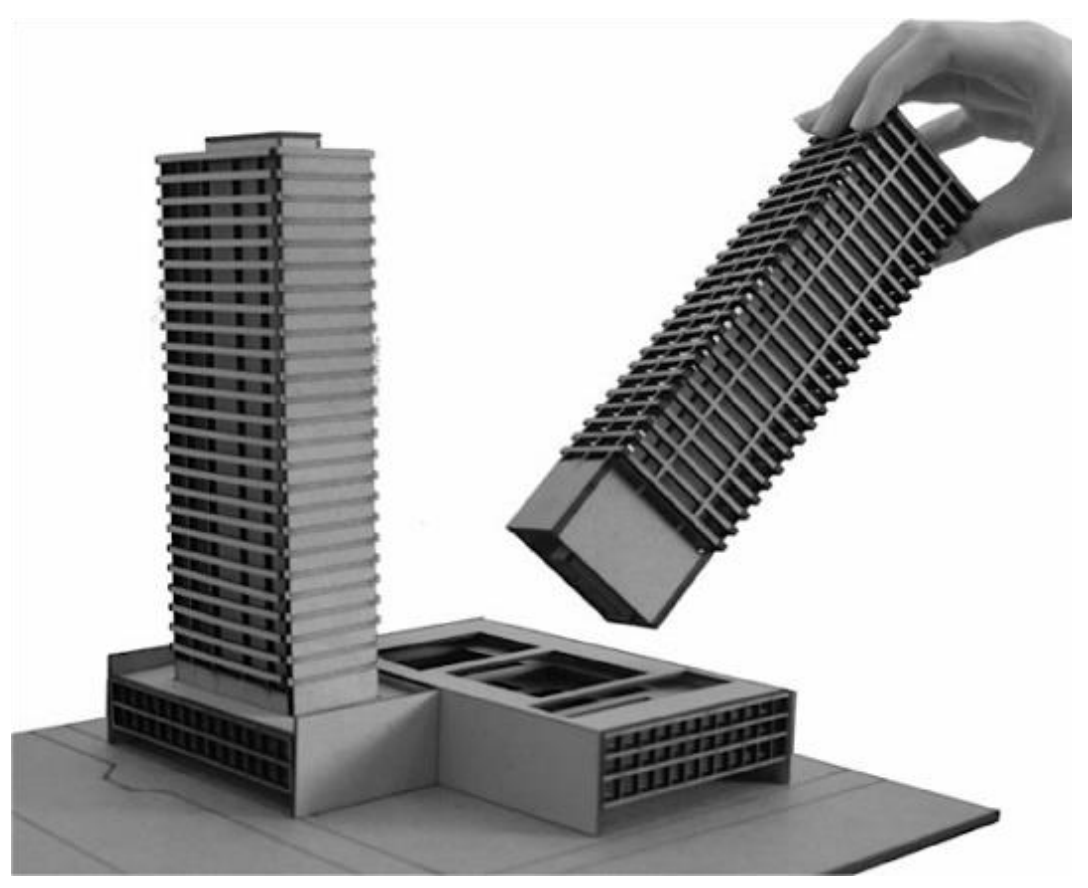




\section{Foto: LPPM}

Figura 11: Pedregulho, 1946, Afonso Reidy.
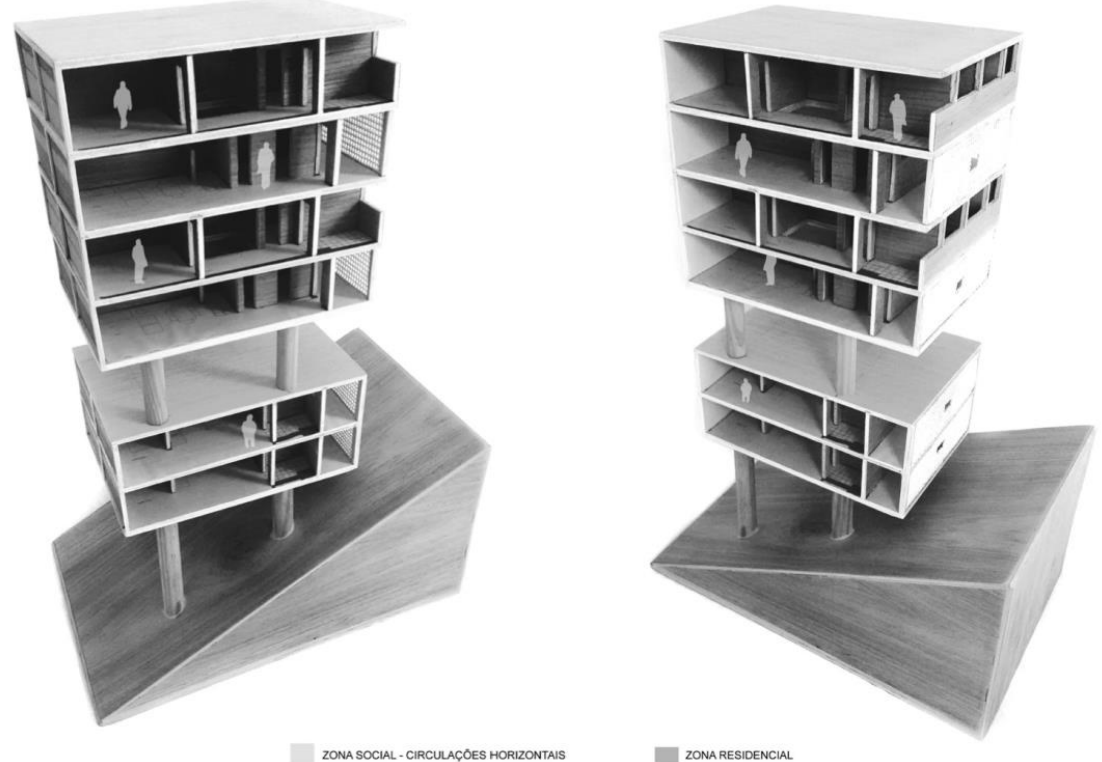

Fonte: LPPM.

A impossibilidade desses dois atores - professor e aluno - se apoiarem em classificações - estilísticas ou não - previamente estabelecidas, exige que se acione um tipo de conhecimento técnico próprio da disciplina, que só é possível a partir de um contato aprofundado com o objeto de estudo. Esse tipo de conhecimento coloca-se de modo diametralmente oposto ao ensino tradicional de história, que se apoia na exposição de imagens e de acontecimentos publicados e republicados na bibliografia canônica sobre 0 assunto.

Outro tipo de exigência anteposta é a necessidade de se buscar ferramentas alternativas de representação, utilizadas em um escritório de arquitetura ou em um atelier de projeto, mas pouco utilizadas nas disciplinas de história.

Para além do conhecimento técnico e das ferramentas de representação, o aprofundamento das relações entre projeto e história induz necessariamente a necessidade de pensar no papel da teoria em relação à prática, muito além de uma história operativa, na formação de um campo disciplinar, que alimente as alternativas de atuação profissional.

Figura 12: Casa para um casal sem filhos, Mies Van der Rohe.

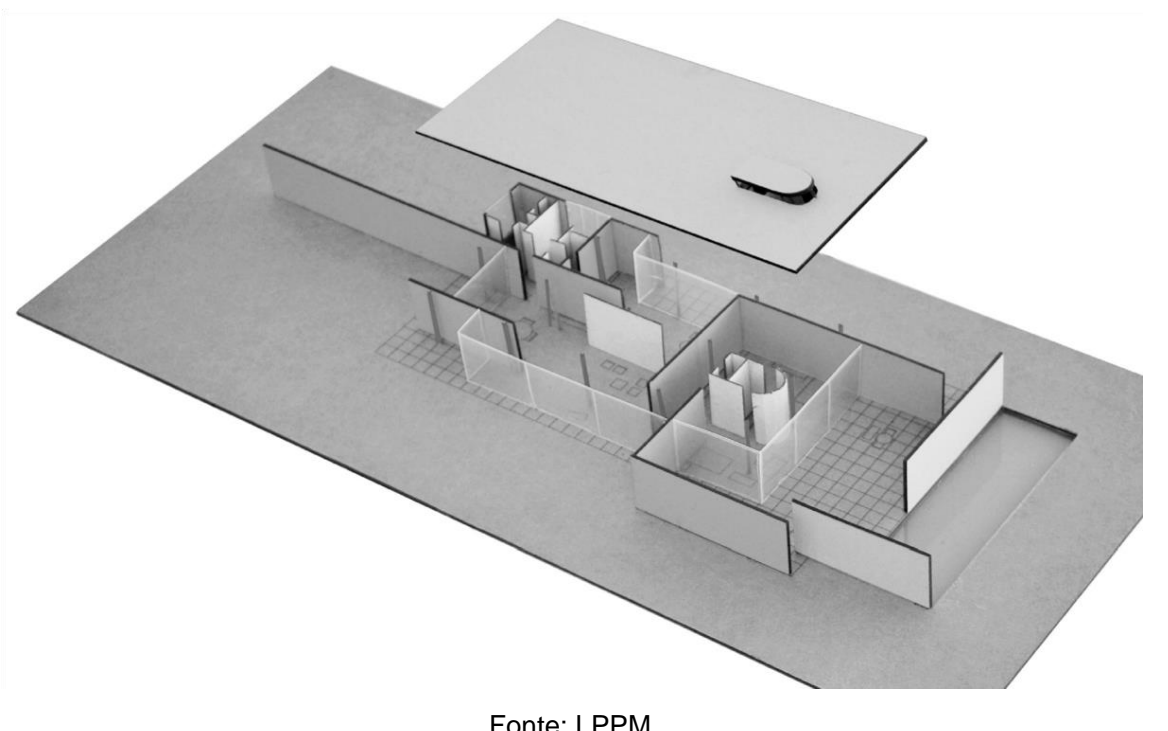

Esse conhecimento produzido exclusivamente a partir do estudo do objeto é entendido aqui como uma base que alimenta a capacidade projetual do estudante/arquiteto, por um lado e, por outro, Ihe permite 
conhecer/aprofundar-se em outro tipo de raciocínio, que parte de um objeto particular, do qual é possível extrair aspectos específicos da sua produção para entender o contexto (tempo e espaço) em que foram realizados, aos moldes da micro-história.

A contribuição da análise gráfica de projetos arquitetônicos exemplares, como ferramenta de aprendizado das disciplinas de história, na formação do arquiteto é da maior importância e tem como objetivo dotar o atelier de história de procedimentos didáticos adequados à integração dos conhecimentos necessários a essa formação. Ou seja, a proposta é um processo ensino-aprendizagem de responsabilidade conjunta docente/discente, na contramão da "tradição do autodidatismo" e/ou do aperfeiçoamento de "talentos inatos". Neste sentido, a sistematização de procedimentos teórico-metodológicos mediados pela análise gráfica - amparada pelo redesenho e modelagem - revela-se instrumento facilitador da apreensão de um conteúdo que é próprio do projeto, a reflexão intelectual sobre o produto gerador de novas propostas.

Figura 13: Edifício Metropolis, São Paulo.

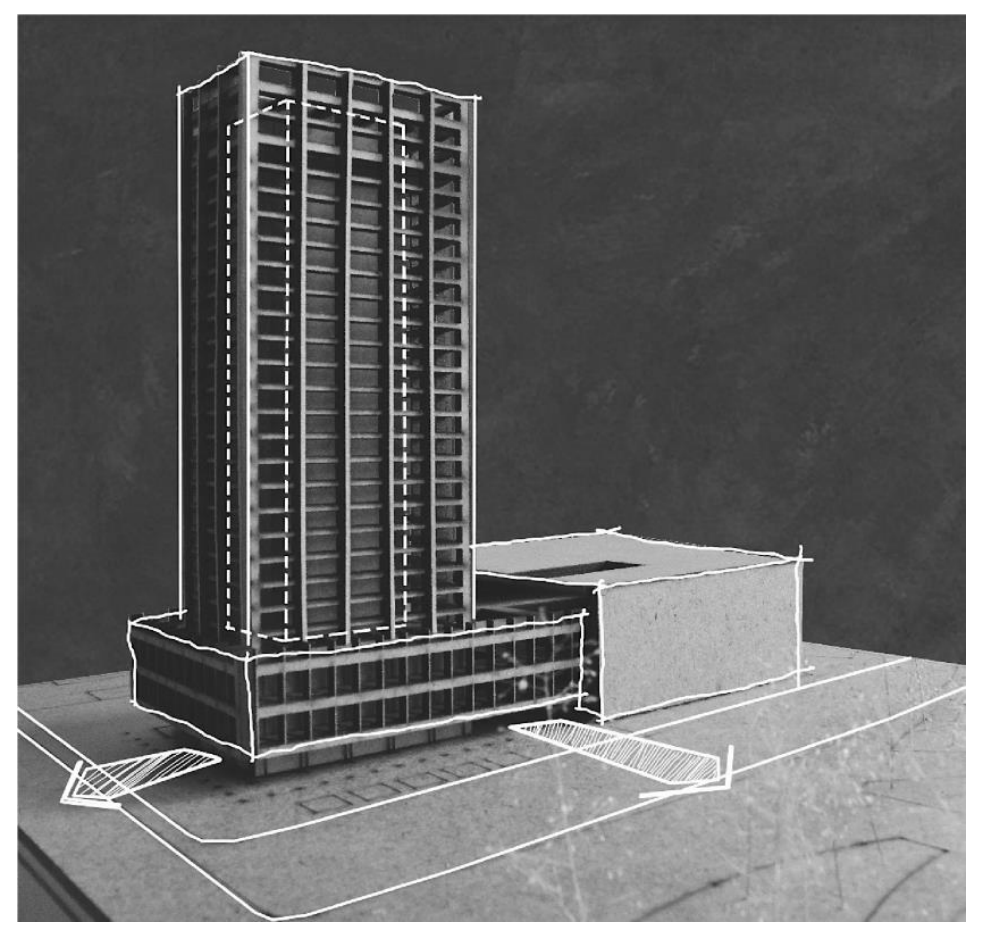

Fonte: LPPM.

Figura 14: Casa Beard, 1934, California, Richard Neutra.

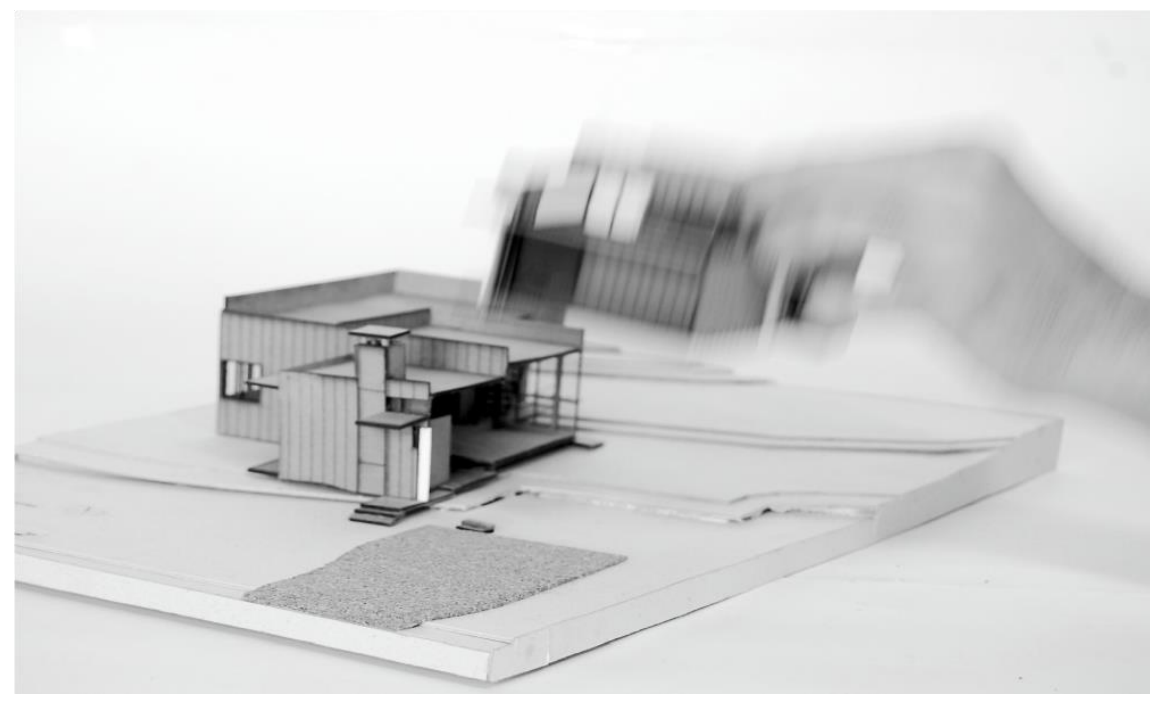

Fonte: LPPM. 


\section{REFERÊNCIAS}

ÁLVAREZ, Fernando; GARNICA, Julio; ESPARZA, Verónica. Entrevista a Fernando Álvarez: maqueta y aprendizaje. "DC. Revista de crítica arquitectónica”, dezembro 2006, n.15.16, p. 63-71, 2006.

BOTELLA, Elena Mata. El análisis gráfico de la casa. E.T.S. de Arquitectura de Madri, 2002. (Tese de doutoramento) COTRIM, Marcio. Construir a casa paulista: o discurso e a obra de Artigas entre 1967-1985. ETSAB-UPC, 2008. (Tese de doutoramento).

COTRIM, Marcio; TINEM, Nelci; VIDAL, Wylnna. Casas de Mario Di Lascio nos anos 1970: rampas, meio níveis e divisão e dois núcleos. Cadernos de Arquitetura e Urbanismo, Belo Horizonte, v. 18, n. 22, maio 2012.

COTRIM, Marcio; VIDAL, Wylnna; TINEM, Nelci. Diálogos gráficos: o uso do desenho mediando aproximações entre história e projeto na formação do arquiteto. In: 7ํFórum de Pesquisa FAU-Mackenzie, 2011, São Paulo. Anais do $7^{\circ}$ Fórum de Pesquisa FAU-Mackenzie. São Paulo: FAU Mackenzie, 2011. v. único.

EISENMAN, Peter. Diez edifícios canônicos 1950-2000. Barcelona: Gustavo Gili, 2011.

HARAGUCHI, Hideaki. A Comparative Analysis of 20th Century Houses. Nova York: Rizzoli, 1988.

ROWE, Colin. The Mathematics of the ideal Villa and other essays. Cambridge: MIT Press, 1976.

\section{NOTAS}

1 Desde 2011, um grupo de pesquisadores do LPPM, Laboratório de Pesquisa Projeto e Memória, vinculado ao Programa de Pósgraduação em Arquitetura e Urbanismo da UFPB, vem trabalhando, nos marcos da pesquisa HM+HC, (lppm.com.br) no que chamamos de ATELIERS DE HISTÓRIA DA ARQUITETURA.

${ }^{2}$ História da Arquitetura e Urbanismo no Brasil II, História da Arquitetura e Urbanismo III e IV.

NOTA DO EDITOR $\left(^{*}\right)$ O conteúdo do artigo e as imagens nele publicadas são de responsabilidade do(s) autor(es). 